\title{
Determinants of Johns' Decision Making: An analysis of a Sex Tourism Web Forum
}

\author{
Ju-Lak Lee \\ Department of Security Management \\ Kyonggi University, Suwon, Republic of Korea
}

\begin{abstract}
Prostitution is one of the oldest professions in human society and the ways sex services are advertised and sought after have changed in recent decades. Specifically, with the emergence of cyberspace which allows for anonymity and secrecy, clients of sex workers, johns, are shown to exchange information in online forums. This method of information sharing is a common practice for those that buy sex in foreign countries, which help them through their decision-making process. In this study, posts in an online forum for the foreign johns in South Korea are examined in order to explore the important factors affecting their decision making.
\end{abstract}

Keywords: sex tourism, web forum, john, prostitution, qualitative analysis

\section{INTRODUCTION}

Prostitution is known as one of the oldest professions [1][2][3] and in addition to its long history, the number of people in the sex industry attests to its prevalence in human society. Statistics show that there are around 13,265,900 sex workers in the world and the revenue generated by the profession is estimated to be $\$ 186$ billion [4].

Sex workers are virtually omnipresent around the world regardless of its legality. Certain nations are more popular for their sex industries than others. In these countries, the sex business has integrated into the economic, social and political sectors over the past several decades, attracting potential clients from all over the globe. Subsequently, it has become an important source of their foreign exchange earnings, which has led to the growth of their sex sectors and sex tourism industries. Therefore, some scholars have argued that economic dominance and power is an important element to be considered, especially in the cases of examining the sex tourism in developing countries [5][6].

Sex tourism is defined as 'the organization of vacations with the purpose of taking advantage of the lack of restrictions imposed on prostitution and other sexual activities by some foreign countries' (Oxford Dictionary). Globalization and technology development have increased the number of sex tourists not only in the countries that are popular destinations for sex tourists but in other parts of the world as well [7]. In addition to the growth of sex tourism, scholars have studied how the technology development has affected different types of subculture populations.

The impact of a rapid advancement in the computer, information, and communications technologies on the development of various deviant sexual subcultures has been investigated by numerous researchers [8][9]. The types of sexual deviances studied include pedophilia (see [10][11]), transsexuals (see [12]), escort services (see [13]), and sex tourism (see [7][14][15]). These studies discuss how the computer technology facilitates information sharing among the 
members of the subculture and establishing their communities. Particularly, [15] has indicated that the advertisements for prostitution tourism to Asia, Europe and South American countries have increased since the growth of the internet and promoted the sharing of sex-related information around the world.

Most of the existing research conducted on sex work has placed an emphasis on the prostitution of the females on the streets. Subsequently, the importance of assessing other types of sex work and different individuals involved in the trade, including the clients has been pointed out in order to understand the phenomenon more comprehensively ([8][16]). In an effort to make a contribution to the literature, this research examines the information sharing and its effect on the johns' decision-making and behavioral patterns by analyzing the forum posts in a sex tourism website. Specifically, this research aims to identify important factors in the johns' search for sex services as foreigners in South Korea.

\section{Research on Johns}

To expand the knowledge on sex work and provide insights into the areas other than the female prostitutes on the streets, researchers have striven to understand the sex work more comprehensively by studying the subculture of johns. Subsequently, it has informed the readers on various aspects of johns, including their behavior, norms, methods of communication, and strategies to avoid detection by law enforcement. In researching the subculture of johns, one of the common types of data that is relied upon is forum posts available to public. The primary reason for utilizing it is its convenience and pristine state immune to researcher contamination [17]. In addition, the interview method has also been employed to research the phenomenology of being a john and sex service websites are examined to investigate how they facilitate sex trade [13] [18]).

According to the findings of related studies, johns do not consider their activities as deviant nor perceive prostitution as an unrespectable profession [3][18][19]. Additionally, even though the johns understand that sex services are something that can be purchased and treat sex providers as a commodity, they value companionship and intimate experiences (i.e. Girl Friend Experience) acquired in the transaction [13][18][19]. This indicates that they wish to fulfill both physical and emotional desires, which is related to a finding that suggests that johns create a setting that makes their practice of meeting and interacting with sex workers as normal as possible and try to appear physically appealing [18].

Based on current literature, johns are aware of potential negative factors, including victimization by prostitutes or their denizens. They understand that the encounters with individuals unknown to them and the illegal nature of prostitution can include possible risk factors [18]. Law enforcement is something that johns are particularly concerned about and they make good use of the relevant information available online to avoid detection. This is shown by the spatial, temporal, and tactical displacement of their activities [20]. As demonstrated by the results, the displacement of johns attests to the argument that computermediated communications seem to be an important resource in shaping johns' decisionmaking by providing information on risks as well as possible alternatives [20].

Furthermore, the amount of available information has increased with technology development in computer and communications and scholars have explored the ways in which the information online is exchanged among johns to promote prostitution offline [8]. The study results show that the online forums simplify the johns' pursuit of sexual services. Specifically, forums are a useful means that helps the johns save their time and effort by providing them with information to find and utilize sexual services off-line [20]. 
The current body of literature demonstrates that johns take advantage of technology development by participating in active information sharing online to search for sex services off-line. In using the wealth of information while exploiting the anonymity afforded in cyberspace to avoid detection by law enforcement and minimize threat to identity [3][8][15][19][20], johns hold a belief that their practice is not sexually deviant or is attached with stigma [15][19]. Finally, in addition to sexual need, the johns researched are found to look for intimacy and excitement from the encounters with sex workers [3][8][13][15][18][19][21].

\section{SOUTH KOREAN CONTEXT}

Based on reviewing the current literature on sex work, the authors have noted that there are gaps to be filled; although valuable insights have been provided by the existing studies, there are no researches that examine the johns' modus operandi in a foreign country. Particularly, there is a paucity of information on how the information-sharing practice online helps the sex tourists find the services they desire off-line.

Traditional sex tourism research has pointed out the importance of economic dominance and undying demand for sex work as the driving force of the sex tourism industry. Most sex tourism studies are heavily focused on the countries such as Thailand, Philippines, Malaysia and Indonesia of the developing region of Southeast Asia that are well-known for their sex tourism industries. Specifically, it reflects the fact that in the Globalized world in which materialism is the dominant philosophy, and with the cost of living is rising, prostitution is a viable alternative for income for those who are poorly educated and unskilled [5].

South Korea has a different economic structure from those of the countries that are popular destinations of sex tourists in Asia. Over the past several decades after the Korean War, South Korea has achieved an unprecedented growth in economy. As the world's twelfth largest economy, its Gross Domestic Product (GDP) was estimated to be \$1.7 trillion in 2013. Furthermore, it is a global leader in computer, communications, and information industries, and is known as the most wired state [22][23].

\section{Prostitution in South Korea}

Despite its illegality and the fact that the South Korean economy does not heavily rely on its prostitution industry, it is prevalent across the country and accounts for as much as four percent of the nation's GDP. According to the Ministry for Gender Equality of South Korea, there are about 500,000 sex workers, and the statistics provided by the Korean Feminist Association is higher, estimating the number at over one million [24].

In the past, the South Korean government made efforts to root out the illegal sex businesses. In 2004, for example, Special Law on Sex Trade 2004 and Act on the Prevention of the Sex Trade and Protection were passed. Unfortunately, the passing of these laws were met with strong opposition from the sex workers and the sex business sector, which led to the establishment of various underground sex providers and diversification of their services. Among different forms of prostitution, Red Light District (RLD), massage parlor, officetel, kiss room, adult barber shop, and juicy bars are the common services available in the country [24].

Officetel, a combination word of office and hotel, is a building used for both commercial and residential purposes. To receive the sex work provided at officetels, customers visit the unit in which a sex provider waits for them, which is aimed to provide protection from detection by law enforcement and simulate the 'visiting your girlfriend's house' experience. Another unique sex business that is not found in other parts of the world is kiss room where the main service 
provided is kissing. Kiss rooms are a suitable example of the emerged sex businesses after the major polices implemented against the sex work industry in 2004.

Moreover, juicy bars sell alcohol and offer sex services upon request and are usually patronized by the U.S. military personnel. They were established when the U.S. militaries arrived after the Korean War ceased on an armistice and were the first sex business that serviced the military personnel and other foreign customers in South Korea. Due to the negative prejudices against servicing foreigners in the country, juicy bar is particularly an important component that needs to be taken into account in this study.

\section{Sex Workers Servicing Foreigners in South Korea}

The earliest sex work aimed to serve foreigners dates back to 1960s when the U.S. military bases were first established in South Korea. Prostitution was allowed around the U.S. military bases as a result of the negotiation between the South Korean and the U.S. government. This was motivated from the fear from the South Korean government that the U.S. army would leave the country, making it vulnerable from the potential attacks by North Korea [25]. The prostitutes that serviced the U.S. soldiers were called "western princesses" and their offspring were stigmatized and discriminated in society. Until today, international marriages are negatively viewed and maintaining the ethnic and homogeneity is the dominant societal norm in South Korea.

The traditional stigma carried in serving foreigners has hindered the process of foreigners' receiving sex services in South Korea. Moreover, cultural biases against them as violent and disease-ridden individuals contribute to the culture within the sex industry that avoids international clients if possible [26]. Furthermore, as mentioned earlier, the country's economic development has generated a large group of financially capable domestic clients that are able to provide a lucrative business, which makes it unnecessary for the local sex workers to serve foreigners. These circumstances separate South Korea from the developing countries that are popular sex tourist destinations with the economic dominance exerted by the foreign clients undermined.

\section{CURRENT STUDY}

In this research, the factors that affect the foreign johns' activities in South Korea are examined. Specifically, by assessing the content of the information shared in an online discussion forum ${ }^{1}$, a theory that explains the johns' behavior is drawn through a qualitative analysis. As mentioned, South Korea is not a popular location for sex tourism compared to the countries in the Southwest Asia and other developing parts of the world. The country's tourist populations have nonetheless grown rapidly due to its economic, cultural, and diplomatic ties with various countries around the world. This increase has been generated partly by the Korea Wave (Hallyu) phenomenon, risen popularity in Korean culture, which started in the 1990s and has changed the perception and national image of South Korea positively [27]. According to the statistics provided by the Ministry of Culture, Sports and Tourism (MCST) of South Korea, there were more than twelve-million tourists in 2013 [28].

\section{Data}

A convenience sample was used for this research; the forum posts within a website (internationalsexguide.info) on international sex tourism were investigated. Among different forums available online, this site provided the most number of relevant posts and information.

1 http://www.internationalsexguide.info 
Posts from other websites were also considered for analysis but did not contain enough information on the sex tourism in South Korea, and the reports available were not recent.

The website used in this research advertises itself as 'The Internet's largest sex travel website,' and provides a wide range of information including the reviews of sex workers, photo galleries, club lists and reviews, location maps, travel information, and discussion forums. A total of 1,293,215 reports posted within 2,247 threads and 354,335 members (at the time of analysis) show the size of this online subcultural community.

For the purpose of this research, The South Korea forum was investigated. Particularly, the thread titled, 'Seoul' was examined because as the capital city, it had the most number of reports $(7,899)$. Considering the volume of posts, only the reports from January 1 to March 31 , 2013 were examined. Although it was not a large portion of the available posts, it was substantial enough (a total of 179 reports) to identify the types of information shared among johns and their behavioral patterns and draw a relevant theoretical conclusion. Based on the information of each report, the johns were heterosexual males who were looking for female sex workers. Although the members' origins of country could not be confirmed, it could be conjectured that most of them were from the United States or other English-speaking countries by assessing their language use and the usernames.

\section{ANALYTIC STRATEGY}

The forum reports were copied and pasted to a word file for analysis. Each post was coded manually and through a three-stage coding scheme, patterns and categories were developed to explain the johns' behavior. Subsequently, the factors that they considered important in searching for sexual services were identified. These Grounded Theory techniques allow researchers to develop an integrated set of concepts that provide a complete theoretical explanation for the subject of research [29]. Therefore, it serves the purpose of this research which is to draw a relevant theory better than any other qualitative analytic methods.

\section{Convenience}

\section{IMPORTANT FACTORS IN JOHNS' DECISION MAKING}

By analyzing the reports in the forum, it was possible to deduce that most of the johns were non-residents and their primary purposes of visiting the country were not sex tourism. One forum member shared his reasons for visit by stating, "Hey people I've been in Seoul for few weeks now for a business trip. I've been staying at a hotel in gangnam and called out few girls for a massage...." Moreover, another person informed others that he was a regular tourist to South Korea: "...In addition to doing a log of business (reasoon for the trip here from the States), I have done five different...." Aside from business purposes, there were johns that lived in or planned to move to the country for work. The U.S. military bases located in several cities, a high demand for native English speakers, and many branch offices of international companies can account for the large foreigner populations in the country.

Considering their temporary status in the country, it was understandable that the johns in the forum could not invest much time in searching for a business that would provide them with the desired services. Therefore, they consistently requested and provided information on a possible destination, including name, location, descriptions, and directions. Moreover, to increase their chances of arriving at their destinations successfully, the johns in the forum often requested and provided maps and images for visual guidance in addition to the directions to and the descriptions of sex businesses. Following is an example of using a link for the road map view of a business when providing directions: “...I seem to remember that between the closure of Moulin Rouge [juicy bar] and whenever CCBar [juicy bar] opened, there 
was some kind of travel agency. You can still see it on the Daum Roadview, picture take June laste year: [link removed]."

Furthermore, another component of convenience that the johns took into account was whether the businesses serviced foreign customers. South Korea is a homogenous society and the female sex workers who service or are married to the U.S. military personnel are historically stigmatized. Even today, international marriage is not common in the country and there are negative stereotypes against the foreigners in regard to their sexual hygiene. Furthermore, numerous past incidents of U.S. military officers victimizing local sex workers have branded them as troublemakers [26].

As demonstrated by the information shared in the forum, convenience was an important factor for the foreign johns in searching for sex services in South Korea. The johns looked for the places that were located near them and tried to acquire detailed directions to and descriptions of the businesses. Moreover, some attempted to act together by forming groups and arranging meetings, which was considered as an effort to minimize mistakes and save time. Furthermore, the johns were aware of the cultural bias against them and patronized the places that accepted them.

\section{Intimacy}

In addition to seeking the sex businesses that were conveniently located and would service them, the johns in the forum placed an emphasis on having intimate experiences that involved both physical and emotional aspects. This was shown by their discussion on the extent to which they could touch the providers and the types of services provided to them. A suitable example was found in a couple of posts that discussed this matter. A forum member asked another person who had reported his experience with a provider, "...Now, in your report, you didn't give any indication whether you were allowed to touch / roam your hands over any parts of the 20-something lady who finished you off. Can you?" and the reply stated, "Touching is allowed; in fact she will climb all over you to kiss your body. I've never had the chance to roam beyond her boobs, so maybe you will have more luck. Let us know."

The emphasis on intimate sexual experiences was reflected by the frequent discussions of the services provided that would give the johns GFE. In the related posts, johns shared details of their positive experiences, and showed frustration and disappointment when the services did not meet their expectation. The posts showed that the physical features as well as the services provided by sex workers were also important elements of intimacy. Furthermore, price was a crucial factor in shaping the johns' perception on their experiences and when the johns felt as though they were cheated or did not get their money's worth, it affected their experiences negatively.

The johns who offered recommendation included information on the type of business in addition to other related details since it was relevant to the available services. Moreover, the names of businesses and providers were mentioned, which were supposed to help others avoid the places linked to past negative experiences.

\section{Security}

Despite its prevalence, prostitution is a prohibited business in South Korea. Therefore, law enforcement was something that the johns in this forum were concerned about when looking for sex services. Consequences of detection by law enforcement may lead to job loss, deportation, or scarred identity. Even though the johns in the forum did not appear to be 
familiar with the South Korean culture or the language, they understood the seriousness of engaging in buying sex services in the country.

Furthermore, the johns in the forum were concerned about falling victim to possible scams. Although numerous opportunities were present on- and offline to order sex services, the johns in the forum showed suspicion toward and were reluctant to try them. An issue that contributed to the caginess was the lack of their language capability. Following is the conversation between two members about the advertisement they found online. A person with the screen name Cmeeyes posted a question in regard to the information about the type of service provided according to the advertisement online, and another member, JookMeUp, posted a reply by saying, “...I was led to believe that everything was on the table. FS [Full Service], multiple pops, whatever. Of course, bear in mind that I was frightened off by the insistence on a pre-meeting deposit, so I never went ahead with it...."After the reply posted by JookMeUp, Cmeeyes tried to order services online and shared his experience.

According to the results, the johns in this forum were aware of the possible risk factors related to their activities. In addition to the aspects of convenience and intimacy, they tried to avoid detection by law enforcement and falling victim to scams. Through the analysis of the reports posted, it could be concluded that the johns in this forum engaged in their activities rationally by weighing the advantages and disadvantages of their actions and reviewing available options carefully.

Table 1. The Process of Grounded Theory Techniques for the Analysis

\begin{tabular}{|c|c|c|}
\hline Open Coding & Axial Coding & Selective Coding \\
\hline $\begin{array}{l}\text { Business Location (BL) } \\
\text { Business Name (BN) } \\
\text { Detailed Business Description (DBD) } \\
\text { Directions (DIR) } \\
\text { Joint Mongering (JM) } \\
\text { Language Issue (LI) } \\
\text { Self-Description (SED) } \\
\text { Unable to Enter (UE) }\end{array}$ & $\begin{array}{l}\text { Convenience: } \\
\text { Searching for places } \\
\text { that can be visited at } \\
\text { one's convenience }\end{array}$ & \multirow[t]{3}{*}{$\begin{array}{l}\text { The johns in the forum want to } \\
\text { maximize their chances of having } \\
\text { positive experiences by saving time, } \\
\text { money, and effort and avoiding negative } \\
\text { elements; and language is an underlying } \\
\text { factor in their activities. }\end{array}$} \\
\hline $\begin{array}{l}\text { Actions Allowed (AA) } \\
\text { Business Type (BT) } \\
\text { Concern About Overpayment (CAO) } \\
\text { Girl Friend Experience (GFE) } \\
\text { Language Issue (LI) } \\
\text { Provider Description (PD) } \\
\text { Provider Name (PN) } \\
\text { Price (PR) } \\
\text { Recommendation (RECO) } \\
\text { Service Description (SD) }\end{array}$ & $\begin{array}{l}\text { Intimacy: Seeing } \\
\text { intimate encounters } \\
\text { and reasonable } \\
\text { payment }\end{array}$ & \\
\hline $\begin{array}{l}\text { Concern About Disease (CAD) } \\
\text { Concern About Law Enforcement } \\
\text { (CALE) } \\
\text { Concern About Scam (CAS) } \\
\text { Concern About Transgendered } \\
\text { Worker (CATran) } \\
\text { Language Issue (LI) }\end{array}$ & $\begin{array}{l}\text { Security: Making } \\
\text { effort to manage } \\
\text { risks by avoiding } \\
\text { negative elements } \\
\text { associated with } \\
\text { buying sex services }\end{array}$ & \\
\hline
\end{tabular}

\section{DISCUSSION}

In this study, a publicly available web forum was analyzed to understand the johns' decisionmaking and behavioral patterns in a foreign country. Specifically, by placing the context of 
research in South Korea, the author attempted to provide a suitable explanation by identifying the factors that affected the johns' modus operandi. Using Ground Theory techniques, three interconnected categories were created to represent the critical elements; Convenience, intimacy, and security were what the johns in the forum valued when looking for sex services. Furthermore, lack of language proficiency was found to be the underlying factor in the overall practice of the johns.

The significance of this paper is in its value of examining the johns in a foreign context by using an available web forum. Since there is a paucity of research on the behavior of johns in a foreign country, the results of this study are expected to provide useful insights into the current knowledge in the related fields. Furthermore, though it may not be of a traditional type, foreign johns' practice of buying sex in South Korea is a form of sex tourism in which the johns' primary purpose of travel is work. A unique feature of this cultural context is that the foreigners have more difficulties in receiving sex services compared to other countries that are popular sex tourist destinations due to the country's advanced economic status and the existing negative prejudices against them. This could have stimulated the adventure and fantasy-fulfillment aspects of buying sex services that have been pointed out in the past studies [6][18].

Several findings support the past results of the studies on johns, including the use of argot to communicate among themselves and viewing the sex workers as a commodity. In addition, bounded rationality provides a suitable explanation for the theory drawn from the analysis. The results of this research must be interpreted with caution due to the lack of a systematic guideline used to confirm the validity of the posts uploaded. However, an active exchange of experiential accounts and subsequent request for further information among the forum members improved the validity of the content. Moreover, the researcher's familiarity with the geography of the city was advantageous in distinguishing the reports that were reliable from those that were not. Nonetheless the results must not be generalized to other populations of johns in other settings.

The existing literature shows that the members of online subculture utilize the computer and communications technologies to share information. The subculture of johns is not an exception and the scholars in the related fields have examined their norms and behavior with a basis on the data available online. Despite their effort, few studies have been conducted on the johns that engage in buying sex services in foreign countries. Therefore, future researches must be carried out on the subculture of johns in a foreign setting more extensively, and different types of data, including interview and survey should be utilized more to improve the current knowledge.

\section{References}

Kumar, T. B. C. (1978). Sociology of Prostitution. Kerala: Kerala Historical Society.

Mathur, A. S., \& Gupta, B. L. (1965). Prostitutes and Prostitution. Agra: Ram Prasad.

Sharp, K., \& Earle, S. (2003). “Cyberpunters and cyberwhores: Prostitution on the Internet.”

Pp. 36-52. In Dot Cons. Crime, Deviance and Identity on the Internet, edited by Y. Jewkes. Portland: Willan Publishing.

Havoscope (2014). Number of Prostitutes in the World. Retrieved from www.havoscoped.com/number-ofprostitutes/

Lim, L. L. (Ed.). (1998). The sex sector: The economic and social bases of prostitution in Southeast Asia. International Labour Organization. 
Ryan, C., \& Kinder, R. (1996). Sex, tourism and sex tourism: fulfilling similar needs? Tourism Management, 17(7), 507-518.

Clancy, M. (2002). The globalization of sex tourism and Cuba: A commodity chains approach. Studies in Comparative International Development, 36(4), 63-88.

Holt, T. J., \& Blevins, K. R. (2007). Examining sex work from the client's perspective: Assessing johns using on-line data. Deviant Behavior, 28(4), 333-354.

Quinn, J. F., \& Forsyth, C. J. (2005). Describing sexual behavior in the era of the Internet: A typology for empirical research. Deviant Behavior, 26(3), 191-207.

Durkin, K. F., \& Bryant, C. D. (1999). Propagandizing pederasty: A thematic analysis of the on-line exculpatory accounts of unrepentant pedophiles. Deviant Behavior, 20(2), 103-127.

Quayle, E., \& Taylor, M. (2002). Child pornography and the Internet: Perpetuating a cycle of abuse. Deviant Behavior, 23(4), 331-361.

Gauthier, D. K., \& Chaudoir, N. K. (2004). Tranny boyz: Cyber community support in negotiating sex and gender mobility among female to male transsexuals. Deviant Behavior, 25(4), 375-398.

Castle, T., \& Lee, J. (2008). Ordering sex in cyberspace: a content analysis of escort websites. International Journal of Cultural Studies, 11(1), 107-121.

DeCurtis, C. (2003). Prostitution, Sex Tourism on the Internet: Whose Voice is Being Heard? Computers and Society, 33, 3-11.

Hughes, D. M. (2004). Prostitution online. Journal of Trauma Practice, 2 (3-4), 115-131.

Weitzer, R. (2005). New directions in research on prostitution. Crime, Law and Social Change, 43(4-5), 211-235.

Silverman, D. (2001) Interpreting Qualitative Data: Methods for Analyzing Talk, Text, and Interaction, $2^{\text {nd }}$ ed. Thousand Oaks: Sage Publications.

Holzman, H. R., \& Pines, S. (1982). Buying sex: The phenomenology of being a john. Deviant Behavior, 4(1), 89116.

Blevins, K. R., \& Holt, T. J. (2009). Examining the virtual subculture of johns. Journal of Contemporary Ethnography, 38(5), 619-648.

Holt, L. J., Krutchinsky A. N., \& Morgan, D. O. (2008). Positive feedback sharpens the anaphase switch. Nature, 454(7202), 353-357.

Xantidis, L., \& McCabe, M. P. (2000). Personality characteristics of male clients of female commercial sex workers in Australia. Archives of Sexual Behavior, 29(2), 165-176.

Central Intelligence Agency (2014). Korea, South. In The world factbook. Retrieved from https://www.cia.gov/library/publications/the-world-factbook/geos/ks.html

Fackler, M (2007, Nov. 18). In Korea, a Boot Camp Cure for Web Obsession. The New York Times, Retrieved from http://www.nytimes.com

Ghosh P. (April. 29, 2013). South Korea: A Thriving Sex Industry In A Powerful, Wealthy Super-State. International Business Times, Retrieved from www.ibtimes.com

Choe, S. H. (January 7, 2009). Ex-Prostitutes Say South Korea and U.S. Enabled Sex Trade Near Bases. The New York Times, Retrieved from http://www.nytimes.com

Moon, G. (Sep. 30, 2011). After soldier held for rape, U.S. vows assistance. Korea JoongAng Daily, Retrieved from http://koreajoongangdaily.joins.com/news/article/article.aspx?aid=2942170

Lee, S. J. (2011). The Korean Wave: The Seoul of Asia. The Elon Journal of Undergraduate Research in Communications, 2 (1), 85-93

Ministry of Culture, Sports and Tourism (2014). Foreign Tourists. Ministry of Culture, Sports and Tourism, Retrieved from http://www.index.go.kr

Corbin, J. M., \& Strauss, A. (1990). Grounded theory research: Procedures, canons, and evaluative criteria. Qualitative sociology, 13(1), 3-21. 